\title{
The use of information and communication technologies for teaching anatomy
}

\begin{abstract}
Introduction: The advent of information and communication technologies has led to significant developments in the field of medical education. These technologies have positive impacts particularly in the learning of many medical disciplines such as anatomy. The introduction of ICT in anatomy has already taken place in many medical schools. ICT constitute a large and inexhaustible database, even if not all sources have the same reliability.
\end{abstract}

Materials and methods: One hundred and thirty-three students of license 1 and license 2 of medicine were subjected to a survey on several aspects of ICT (logistics, use of a smart phone, frequency and duration of connection to the internet, type of website visited to learn anatomy, language used, IT students' experience, training materials).

Results: A majority of students owned a computer and were able to perform word processing and power point presentations. Many students use to connect with their smart phones, and usually visit anatomy websites. Through this work, the students also exposed the strengths and limits of the use of ICT in anatomy.

Conclusion: ICT has become a catalyst for change in university education. In the area of the learning of anatomy, this is an undeniable progress. ICT represents an extremely efficient means of communication, which will be less and less expensive.

Keywords: information and communication technologies, anatomy, learning, training
Volume 7 Issue 2 - 2020

\author{
Philippe Manyacka MA Nyemb 1,2 \\ 'Laboratory of Anatomy and Organogenesis, Gaston Berger \\ University, Senegal \\ ${ }^{2}$ General Surgery Service, Regional Hospital, Senegal
}

Correspondence: Philippe Manyacka MA Nyemb, Laboratory of Anatomy and Organogenesis, UFR 2S, Gaston Berger University, Road of Ngallelle, 234 Saint-Louis, Senegal,Tel (+22I)

7744543 13, Email philippe-manyacka.manyemb@ugb.edu.sn

Received: March 03, 2020 | Published: March 30, 2020

\section{Introduction}

Information and communication technologies (ICT) bring together all the tools that make it possible to use, transfer or share digital data from media, through social networks or via the internet. These new technologies have become a common source of information for medical students. ${ }^{1,2}$ They allow greater dissemination of information and better interactivity, making it possible to promote both individual and collective work. The incursion of these new information and communication technologies therefore leads to significant developments in the field of education. These technologies have various impacts in the learning of many medical disciplines such as anatomy. ${ }^{3,4}$ In anatomy, ICT allow several generations of students to progressively move from a limited space in the laboratory to a space of communication outside of time and place. Through this study we wanted to report on the level of equipment of medical students, their experience in the use of computer tools for learning anatomy, and their expectations of ICT in comparison to classical lectures.

\section{Materials and methods}

One hundred and thirty-three license 1 and license 2 medical students participated in the survey. The sample of 133 students represented the entire first and second years population of the medical course. The abstention rate was therefore 0 . The survey took place at the end of the academic year of anatomy. The investigation focused on different aspects of the use of information and communication technologies by medical students. These aspects included: logistics, use of a smart phone, frequency and duration of connection to the internet network, type of website visited to learn anatomy, language used, computer students experience, training materials. Students had 60 minutes to answer questions. Students were interviewed using short, simple and understandable questions. A space was reserved on the questionnaire for the students' free comments.

\section{Results}

The students were 18 to 23 years old (average 20.5 years). The sample consisted of 98 male and 35 female students. The more detailed results are shown in Appendix \& Figure 1-8. 89 of the 133 students owned a computer while 44 did not. However, 34 students regularly used a computer without owning one.

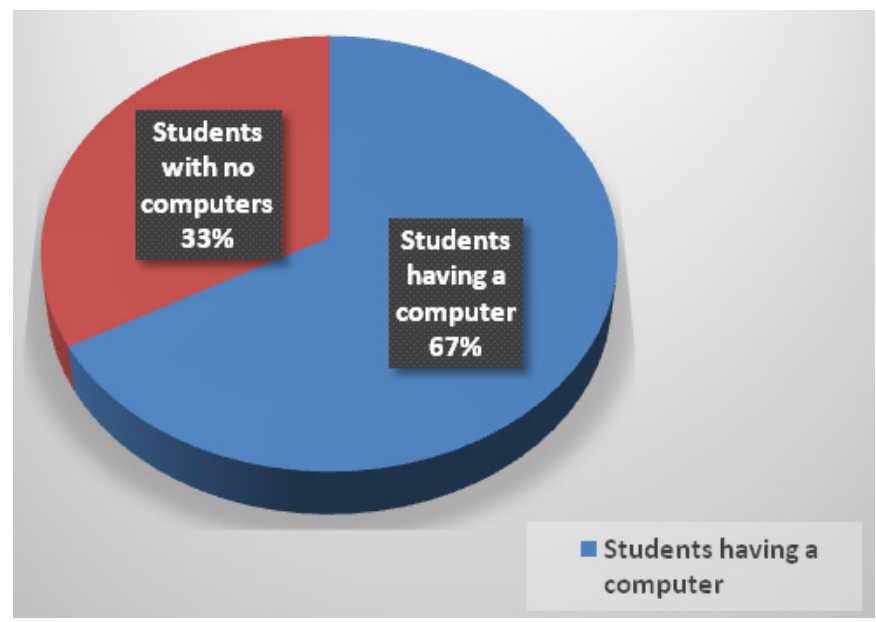

Figure I Students owning at least one computer. 


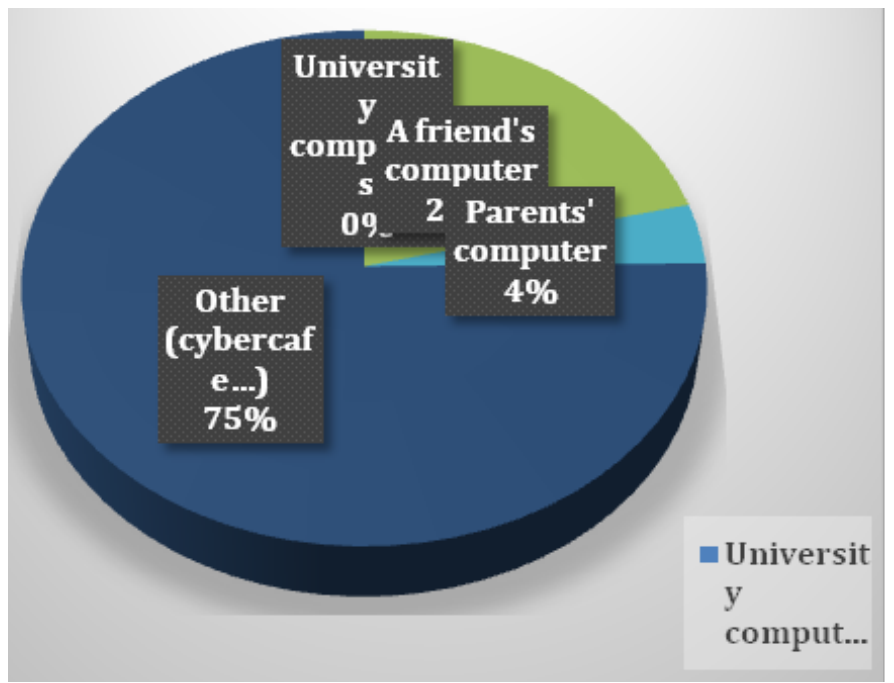

Figure 2 Answers of students that borrow a computer for the learning of anatomy.

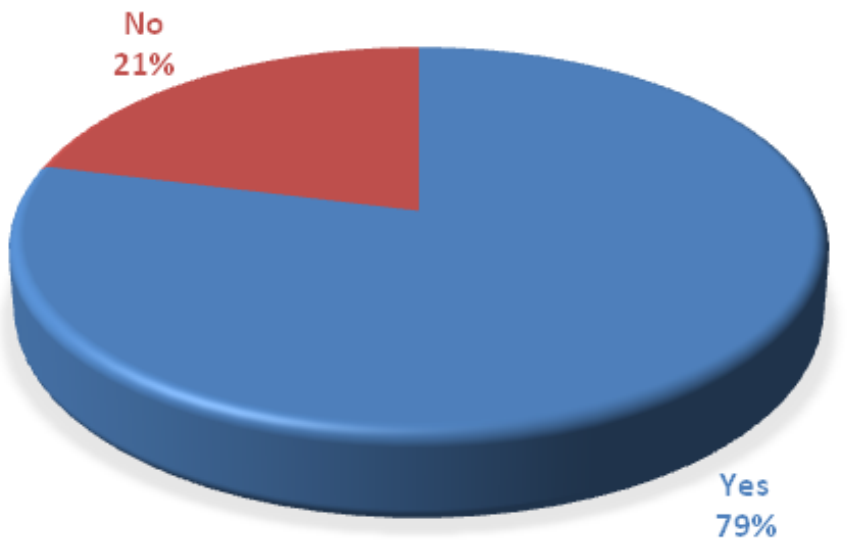

Figure 3 Proportion of students (yes) who regularly connect to internet with their smartphones for the learning of anatomy.

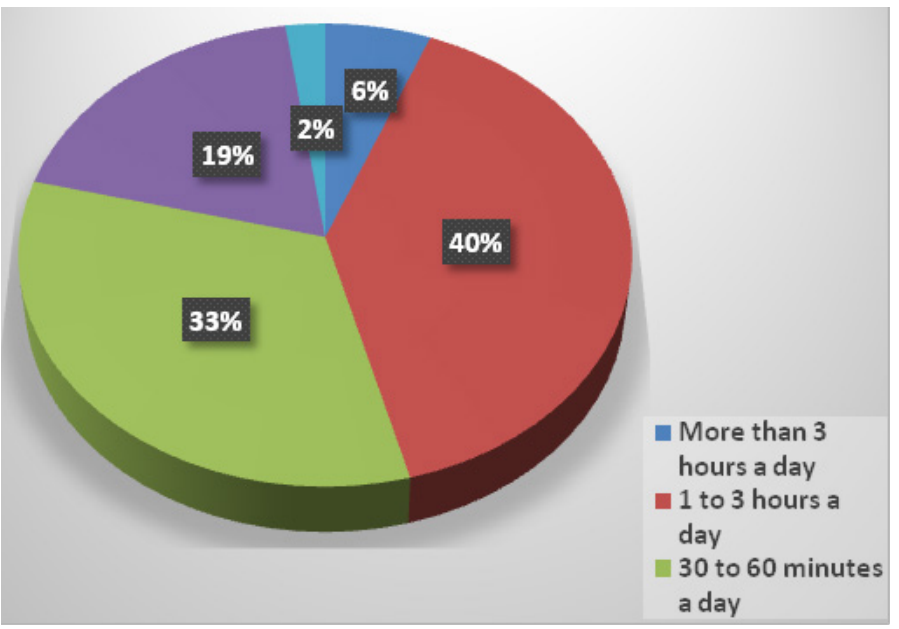

Figure 4 Estimated time spent online.

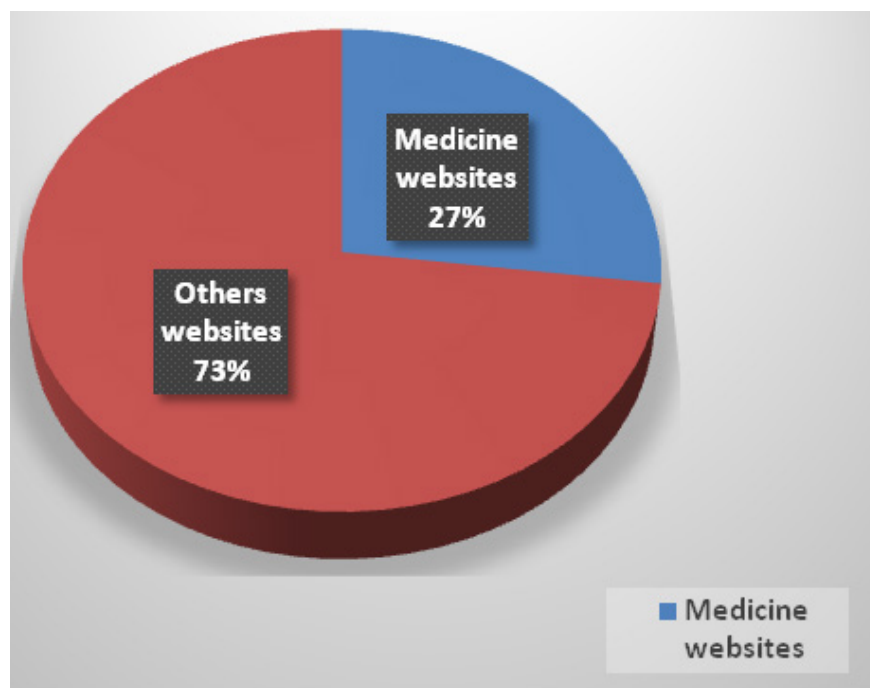

Figure 5 Types of websites visited by students.

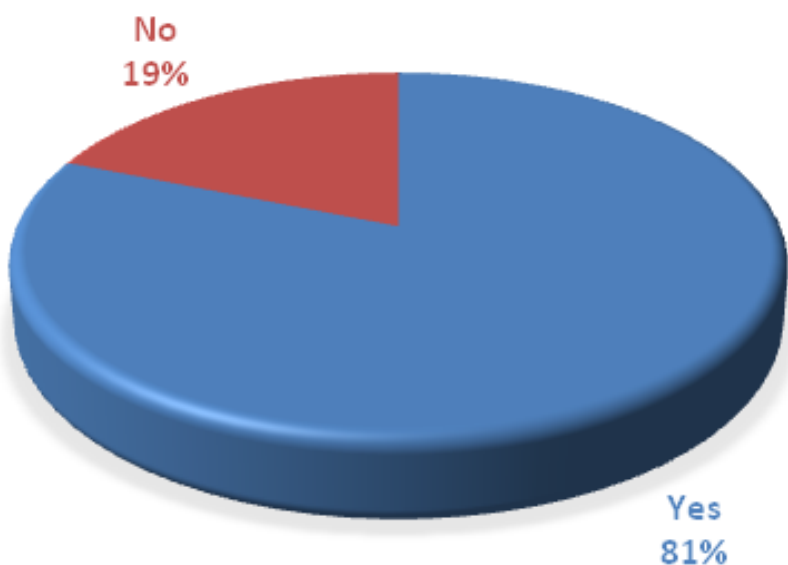

Figure 6 Proportion of students (yes) who have ever visited an anatomy website.

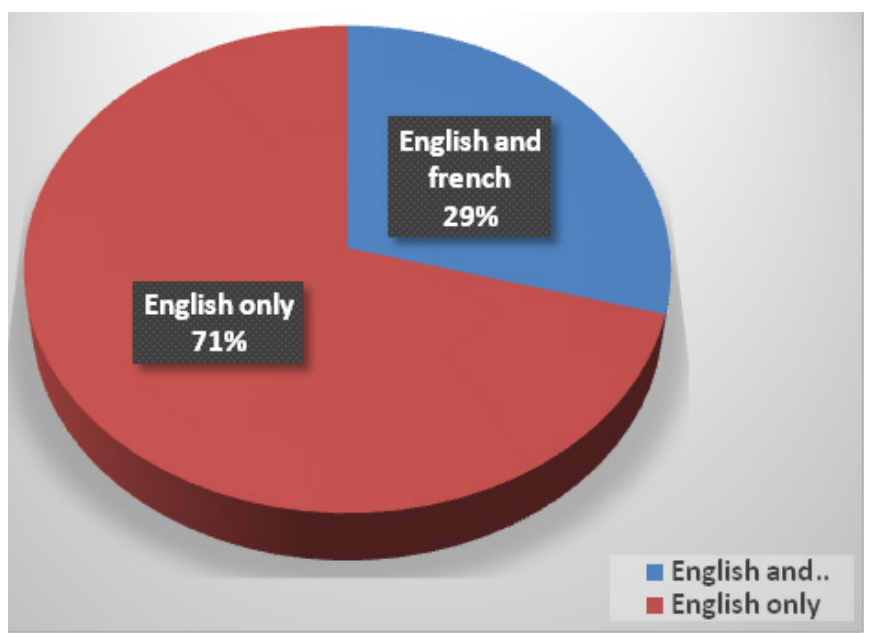

Figure 7 Language(s) used on the visited websites. 


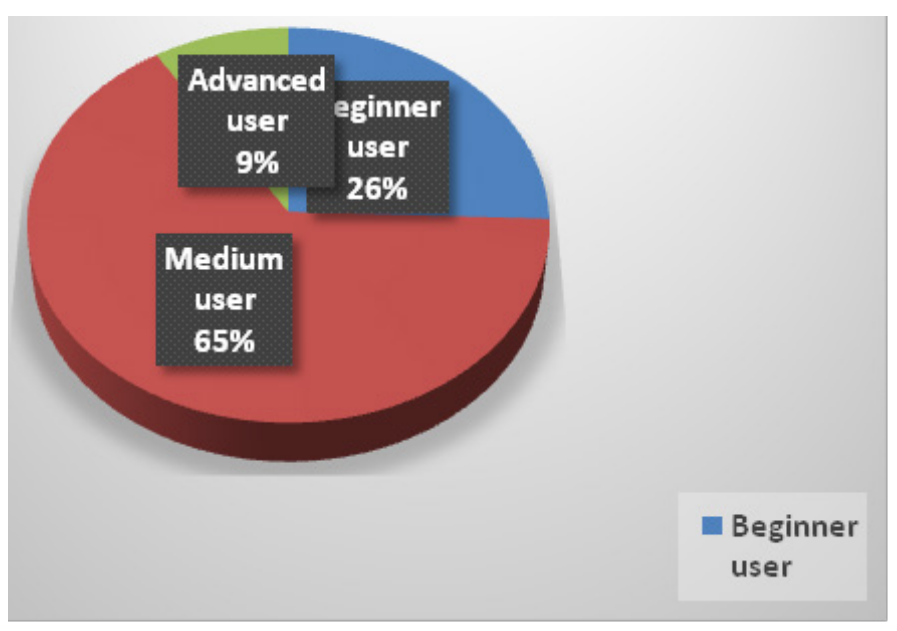

Figure 8 Experience of medical students in the use of Information and Communication Technologies.

Of the 133 students interviewed, 114 were able to do word processing on "Microsoft Word" and 97 were able to design a slide presentation on "Microsoft PowerPoint". In addition, 09 students usually used training CDs (compact discs); and 45 students used computer books.

In comments, the interviewed students reported some limitations regarding the use of new information and communication technologies for teaching anatomy. Students should be provided with a list of approved websites to avoid surfing on unreliable sites. A list of electronic books should also be provided. Students deplore the lack of computer tools (computers, tablets, etc.), this constitutes an important limitation both for anatomy and for other disciplines taught in License 1 and License 2 of medicine. The WIFI signal is very low in the university campus, and the internet connection is generally of very poor quality within Gaston Berger University in Saint-Louis. The anatomy courses in pdf format are difficult to assimilate. In general, students prefer blackboard lessons. Some students also believe that learning the anatomy course through a computer screen exposes to health risks: visual fatigue, sleep disturbance, muscle tension related to bad postures, ergonomic concerns. Emphasizing the teaching of anatomy through the use of new information and communication technologies disadvantages students who do not have a computer. Teaching on the blackboard has the advantage of putting all students on a same level of equality.

Several students have also demonstrated the benefits of using new information and communication technologies. Illustrative videos on "YouTube", "Google" and "Facebook" are used by many medical students to improve their understanding of the anatomy course. This trend is growing among students and this approach is part of a selftraining logic. New information and communication technologies represent an important database, although the fact that some of the sources are unreliable. These days, these technologies are essential, whether during medical studies or during medical practice.

\section{Discussion}

Our work shows that $67 \%$ of anatomy students have a computer (Figure 1\&2). However, those who do not have any computer use another one, $44 \%$ of anatomy students are in this case. Furthermore, even in the absence of a computer, our work shows that almost $79 \%$ of students regularly connect to the Internet using their smart phones (Figure 3).

The implementation of ICT in the practice of medical pedagogy, in a university or hospital environment, represents a major challenge. In the wider field of university pedagogy and NICT (new information and communication technologies), there are numerous references and publications on the issues to be considered, in order to promote such a change. ${ }^{5,6}$ The scientific literature in the field of university education seems to show that there is somehow a dilemma facing university trainers: "must the container (teaching method) adapt to the vehicle (technology) or that the vehicle should adapt to the container".? Current research in the field of university pedagogy seems to show that pedagogy must be the main priority and that it is up to technology to adapt. However, recent studies also show that pedagogy can evolve when it is in contact with new technologies. ICT therefore become, in certain contexts and according to specific uses, catalysts for change in university pedagogy. The experience of Nosek et al. ${ }^{8}$ is a good example of a situation where technology has served as a catalyst for innovation in teaching practices. Their experience report trainers who wanted to make learning more active, while facing large groups. The use of clickers by participants during lectures has encouraged active learning and increased student interest. In addition, their study shows an improvement in the performance of future doctors (during official exams) after participating in such an experiment. Although the benefits of the use of ICT in education have been widely emphasized in other contexts, ${ }^{9}$ they have been much less emphasized in the field of medical education, and in particular in the teaching of anatomy. ${ }^{10}$

Many advances linked to the use of ICT in medical practice resulted to an impact on training: the typical example is the teaching of anatomy, which has been completely transformed by the progress of imagery. The last few years have seen the development of numerous websites devoted to medicine. They are estimated at 15 to 20,000 , including nearly 3,000 websites in French. They are managed by public institutions (ministries, universities, organizations, learned societies, hospitals, private companies, pharmaceutical laboratories or communication firms). They are aimed at both healthcare professionals and the general public. They are sometimes more oriented towards the journalistic approach, sometimes more towards training. The application of ICT will fundamentally change our role as a teacher of anatomy. The teacher will gradually become a facilitator, a guide to learning and no longer just a reservoir of knowledge. However, it should be noted that this evolution is not due to new technologies themselves, but to an evolution of modern pedagogy, centered on the learner. Different systems allow them to self-assess, that is to say, to check whether they have mastered the expected knowledge. In this way of teaching and learning, ICT naturally find their place.

In our work, $75 \%$ of students are likely to use a computer other than their own. However, we can ask ourselves the question of what is the real use of the training tools made available to our students? Despite having Internet access at their disposal, a significant proportion of students make very little use of the didactic tools and educational resources available online.

However, our results partially joint those of Reding et al. ${ }^{11}$ Who showed in 2001 that a majority of students considered themselves insufficiently trained in the use of new information and communication technologies and favored the assimilation of the discipline taught via printed documents. 
A short review of the literature ${ }^{12}$ published in 2003 showed that the real potential of NICT for education cannot be limited to a technological approach: the computer, superimposed on traditional forms of teaching does not improve the quality, nor the performance of teaching. Furthermore, the benefits expected from the use of NICT should not be limited to the only sphere of knowledge. Particularly in anatomy, the introduction of new techniques requires an in-depth restructuring of teaching methods. It also appears that the insertion of new technologies does not automatically lead to the introduction of new teaching methods.

Our work also reports that $73 \%$ of students spend daily 30 minutes to 3 hours on the internet network (Figure 4). This explains why a majority of students $(65 \%)$ have an acceptable average mastery of computer tools (Figure 8). Although this duration does not reflect the time spent on an anatomy website, it shows that most students are used to surfing the net. Medicine websites are only regularly visited in $27 \%$ of cases, but more than $80 \%$ of students have already visited anatomy websites (Figure $5 \& 6$ ).

The introduction of NICT in anatomy has already taken place in many medical schools. NICT constitute a large and inexhaustible database, even if not all sources have the same reliability. These technologies have become essential these days, whether during medical studies or during medical practice. Anatomy videos on "YouTube", "Google" or "Facebook" are used by many students to improve their understanding of the lecture. This trend is more and more observed today, in the era of self-training.

The work of Karsenti \& Charlin ${ }^{2}$ presents a review of the main impacts and challenges posed by information and communication technologies (ICT) on the practice and teaching of medicine. With ICT, everything changes: the way we live, learn, work, and even socialize. These societal metamorphoses have accelerated since the arrival of Web 2.0, which allows Internet users to interact not only with the content of pages but also with each other. Several studies have highlighted the shortcomings of medical schools with regard to the integration of ICT in initial or continuing medical education. For example, Suarez ${ }^{13}$ indicates that there is little training or introduction to ICT applied to health in most initial medical education courses. However, several authors ${ }^{10,14,15}$ maintain that learning the use of ICT should imperatively be part of the initial and continuous training of doctors, because they are on the one hand, omnipresent in their work context and, on the other hand, essential for updating knowledge in a field where knowledge is constantly evolving. In our context at Gaston Berger University in Saint-Louis, the use of ICT is very present.

There are many technological resources that can be applied to the training of health science professionals. Mattheos et al. ${ }^{16}$ have attempted to identify them. These include databases, computerbased learning (including 3D virtual animations, educational games, simulators and e-learning) and virtual communities. Valcke \& De Wever ${ }^{10}$ point out that knowing how to access online resources, that is to say having information literacy, must also be part of the initial training of future doctors.

The visual presentation of information is fundamental in the acquisition of a medical knowledge, this is all the more true in the teaching of anatomy. Graphic representations can facilitate learning, particularly in distance learning contexts where the trainer is not present to comment on the image or the anatomical diagram..$^{10}$ Threedimensional (3D) animations are examples of these representations.
John ${ }^{17}$ specifies that $3 \mathrm{D}$ animations are particularly used in anatomy lessons, and that several studies have shown that they have a positive impact on learning, when they are combined with other types of teaching aids (texts, video clips, etc.). It is therefore not surprising that more and more medical schools are using 3D animations on the Web as part of initial medical education. The whole of the brief scientific literature on virtual simulators undeniably shows the advantage of this use of ICT for medical training. However, as pointed out by Valcke \& De Wever ${ }^{10}$ this is particularly the case: a) when the training is aimed at beginners and $b$ ) when the required technological skills do not constitute an obstacle to the use of the virtual simulator. Again, this argues, in our view, in favor of the need to present such innovations as part of the initial training of future physicians. E-learning is not just about information available in electronic format on the Internet. Rather, it is, according to Ellaway ${ }^{18}$ a pedagogical approach that aims to be flexible centered on the learner and that encourages interactions (teacher-teacher, teacher-student, student-student), collaboration and communication. It turns out that "teaching anatomy on the Internet is associated with favorable effects for a wide variety of students, learning contexts, clinical subjects and learning outcomes".

New information and communication techniques or technologies (NICT) cover a set of tools, based on computers and networks, allowing access to or sharing of data, coded in a digital way, concerning texts, images, sounds. The modalities of medical training have evolved in parallel with the evolution of the supports. For a long time, training was based on the relationship between the teacher and his student. Besides, isn't it still the case? NICT have become a social phenomenon, they have generated multiple books, articles and now have their specialized press. Their advantages and disadvantages have been discussed many times. In a positive way, the NICT allow access to a huge volume of information, in very varied forms, textual, graphic, sound. They represent a liberation in the mode of access to knowledge, liberation of place, but also time, and a way to access knowledge. They allow the integration of information in different forms and their use. In the medical field, this is undeniable progress. They represent extremely efficient means of communication, which will be less and less expensive: Internet messaging is only a small part of the means available; there are also image transfers, discussion forums, videoconferencing, virtual campuses ...

Conversely, ICT are expensive, not only because computers are expensive (less and less, it is true), but above all because educational developments require people capable of using complex systems and because the time needed by teachers for such developments is important. Another danger is the learner's isolation, loss of contact with others students, and with the teacher. This real risk depends fundamentally on the type of relationship targeted by the learning system. Empowerment of learners does not mean dehumanization of relationships between themselves and others. In anatomy, information and communication technologies (ICT) are added to the knowledge transmission instruments that are books, handouts and lectures. Scientific content is currently widely available on the Internet network. It is present without any particular educational intention and often remains the simple transposition of paper documents, associated with more or less abundant imagery. The provision of courses on the Internet is probably not sufficient for learning, because it is not associated with a clear educational approach. But the interactivity of ICT (hypertext links, video, animations, questions-answers and selfassessments) potentially place them among the tools intended for the construction of knowledge as are tutorials. 
Many students wonder if electronic anatomy education has a future and whether ICT is only used to store more knowledge (much written data) in a smaller volume. They regret that the device is not better exploited on the educational level. Having larger handouts in electronic form does not seem to them to be the issue of e-learning. Electronic education "must be new" 19 and must offer new and interactive formulas, using all the possibilities of the computer tool. Electronic teaching is desired by students in order to provide visual support for traditional teaching (illustrations, images, x-rays, animations, video). It is an up-to-date, recent source of information that is constantly updated, as opposed to a book that has to wait for its reissue to be up to date. It is a useful database for carrying out research work. In order for ICT to become more than an informative resource but a true educational content, students' IT equipment must progress, and teachers must improve the use they make of ICT for educational purposes. Even though the availability of IT tools is still uneven among medical students, ICT has taken an important place as a knowledge resource.

\section{Conclusion}

For the teaching of anatomy, NICT represent new communication tools. They are introduced into most if not all sectors of socioeconomic life. Their use in the health world is very advanced. Besides a medical practice tool, they are also training tools for medical students in anatomy. They cannot be limited to the introduction of new supports in anatomy training. They should lead us to rethink our role as a teacher by always looking better at how the student learns, and how we can become guides and animators and no longer reservoirs of knowledge.

\section{Acknowledgments}

None.

\section{Conflicts of interest}

The author declares there are no conflicts of interest.

\section{Funding}

None.

\section{References}

1. François $B$, Michèle $K$, Jacques $M$, et al. Use of information and communication techniques by students in their fourth year of medical studies at the Faculty of Strasbourg (France). Evolution on four promotions. Pédagogiemédicale. 2006;7(1):43-52.

2. Thierry K, Bernard C. Analysis of the impacts of information and communication technologies on the teaching and practice of medicine. Medical Pedagogy. 2010;11(2):127-141.
3. Garg A, Norman GR, Spero L, et al. Do virtual computer models hinder anatomy learning? Acad Med. 1999;74(10 Suppl):S8-S9.

4. Petersson H, Sinkvist D, Wang C, et al. Web-based interactive 3D visualization as a tool for improved anatomy learning. Anat Sci Educ. 2009;2(2):61-68.

5. https://www.puq.ca/catalogue/livres/les-tic-coeur-des-pedagogiesuniversitaires-53.html

6. https://www.puq.ca/catalogue/livres/enseigner-avec-lestechnologies-1578.html

7. Fillion-Carrière $M$, Denis $H$. State of the art of distance continuing medical education in North America. Distances. 2003;6:51-72.

8. Thomas N, Wei W, Irene $\mathrm{M}$, et al. Use of a computerized audience response system in medical student teaching: Its effect on active learning and exam performance. In: E-Learn: World Conference on E-Learning in Corporate, Government, Healthcare, and Higher Education. Association for the Advancement of Computing in Education (AACE), 2006:22452250 .

9. https://www.puq.ca/catalogue/themes/apprentissage-collaboratifdistance-92.html

10. Valcke M, De Wever B. Information and communication technologies in higher education: evidence-based practices in medical education. Med teach. 2006;28(1):40-48.

11. Raymond R, Jean-François D, Philippe P, et al. Access, skills and opinions of medical students to information and communication technologiesResults of a survey of 330 UCL students, Belgium. Pédagogiemédicale. 2001;2(4):242-249.

12. Denef JF, Lebrun M, Donckels F. Tele training, telemedicine, E: Mytheoureality? Medical Leuven. 2003;122(9):S335-S342.

13. Cathy S. Telemedicine: what legitimacy does a radical innovation have for healthcare professionals? IRES review. 2002;39:157-186.

14. Frehywot S, Vovides Y, Talib Z, et al. E-learning in medical education in resource constrained low-and middle-income countries. Hum Resour Health. 2013;11:4.

15. Francis L, Joanna B. A review of e-learning practices for undergraduate medical education. Journal of medical systems. 2004;28(1):71-87.

16. Mattheos N, Stefanovic N, Apse P, et al. Potential of information technology in dental education. Eur J Dent Educ. 2008;12 Suppl 1:85-92.

17. Nigel WJ. The impact of Web3D technologies on medical education and training. Computers \& Education. 2007;49(1):19-31.

18. Ellaway R, Masters K. AMEE Guide 32: e-Learning in medical education Part 1: Learning, teaching and assessment. Med Teach. 2008;30(5):455473.

19. Denef JF. Evaluate new technologies, yes, certainly, but how? Medical Pedagogy. 2003;197-198. 